\title{
Helicopter-borne radio-echo sounding of Svartisen, Norway
}

\author{
Michael Kennett, Tron Laumann \\ Norwegian Water Resources and Energy Administration (NVE), Postbox 5091 Majorstua, 0301 Oslo, Norway
}

Cecilie Lund

State Power Board (Statkraft SF), Postbox 5021 Majorstua, 0302 Oslo, Norway

\begin{abstract}
A helicopter-mounted low frequency ice-radar has been developed for the depth sounding of temperate glaciers. The radar consists of standard transmitter and digital receiver equipment. The long antennae are supported on a special aluminium and fibreglass construction which hangs $20 \mathrm{~m}$ below the helicopter. The radar has been used on Engabreen, an outlet glacier of the Svartisen Ice Cap in northern Norway, where ice thicknesses of up to $350 \mathrm{~m}$ were obtained. The results have been used to construct a map of bed topography of the lower part of Engabreen. This map is largely consistent with ice thickness data obtained by drilling.
\end{abstract}

\section{INTRODUGTION}

Ground-based profiling with low frequency radio-echo equipment is now the standard method of mapping bed topography for temperate glaciers. A centre frequency of around $5 \mathrm{MHz}$ is usual. The equipment is typically towed over the snow surface by snow-scooter, and large distances can be covered efficiently. Problems arise however on many glaciers because of a steep surface slope often accompanied by heavy crevassing. This is indeed the case for most outlet glaciers from Norway's largest ice-caps, including Jostedalsbreen, Svartisen and Folgefonn. Spot measurements can also be made by carrying the radar equipment over the ice surface. However this is time-consuming, and the bed echo is often difficult to identify in individual radar returns. On many glaciers crevassing is too heavy even for spot measurements.

Airborne ice-radar could solve these problems, but the approximately $15 \mathrm{~m}$ long antennae are awkward to mount on an aircraft. Higher frequencies and shorter antennae cannot be used because increased volume scattering from water pockets tends to obscure the bed echo (Watts and England, 1976). Watts and Wright (1981) developed a radar system for fixed-wing aircraft which they used on Columbia Glacier. Using antennae trailing from the wing tips they could measure ice thicknesses up to $1050 \mathrm{~m}$ at a frequency of $1.2 \mathrm{MHz}$ (personal communication from Mark Meier). Profiling with fixed-wing aircraft is however not feasible for the steep narrow outlet glaciers that are typical for Norway. Helicopters on the other hand are ideal aircraft for controlled flying in mountainous terrain.

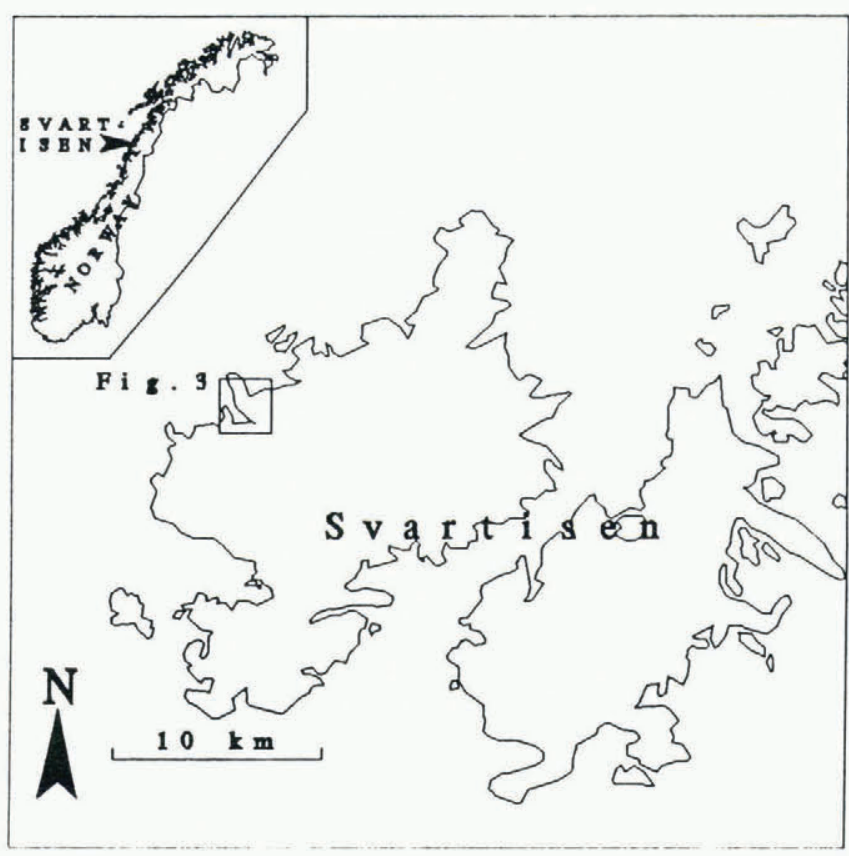

Fig. 1. Location map for Svartisen. The box indicates the Engabreen outlet glacier.

Development of a helicopter-borne radar was therefore initiated at NVE in 1990 in collaboration with Statkraft, stimulated by the requirements of a hydropower project in northern Norway. The radar will be used to help locate the subglacial water channel(s) under Engabreen $\left(66^{\circ} 40^{\prime} \mathrm{N}, 13^{\circ} 45^{\prime} \mathrm{E}\right)$, an outlet glacier from the temperate Svartisen Ice Cap (Fig. 1). The water will 
eventually be captured by a subglacial intake and used to generate hydropower. A tunnel for transport of the water has already been constructed underneath Engabreen. Ice thickness measurements are of vital importance in order to calculate the most likely positions of the water channels and assess their stability, but Engabreen is too steep and heavily crevassed for ground-based radar measurements.

The helicopter-borne radar is now operational and has been used to measure the ice thickness of the lower part of Engabreen. The radar equipment and results from Engabreen are described below.

\section{THE RADAR EQUIPMENT}

The main problem in the development of the helicopterborne radar has been the size of the antennae normally used. The long antennae cannot be mounted on the helicopter body but must hang from the main hook. In the current design, transmitting and receiving antennae are mounted on a horizontal $\mathrm{H}$-shaped structure consisting of four fibreglass poles, each $7 \mathrm{~m}$ long, which are fastened perpendicular to the ends of a $16 \mathrm{~m}$ long aluminium mast (Fig. 2). This hangs approximately $20 \mathrm{~m}$ under the helicopter body. The antennae are fixed inside the poles, aligned perpendicular to the helicopter body so

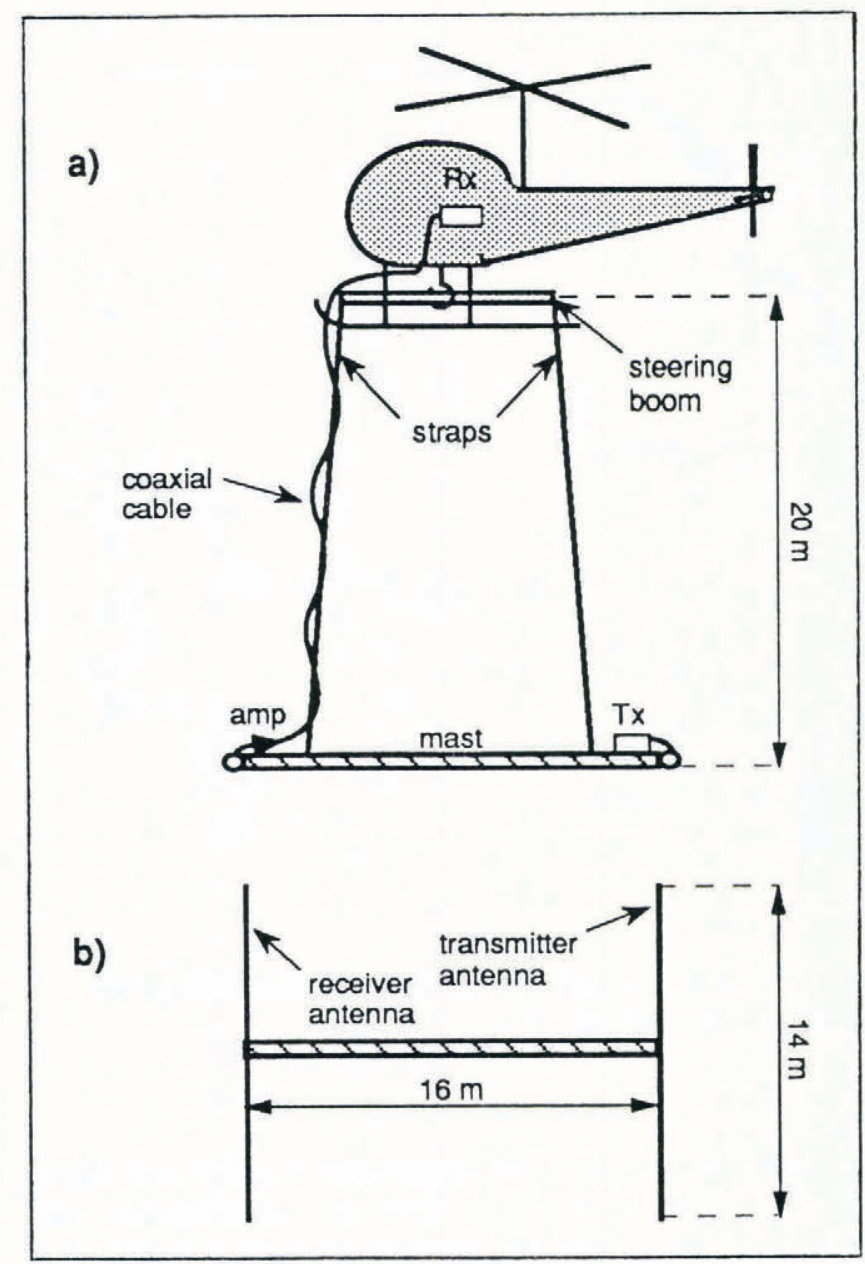

Fig. 2. Antenna support structure hanging from helicopter hook: (a) side view, (b) plan view. Tx, transmitter; $R z$, receiver; amp, amplifier.

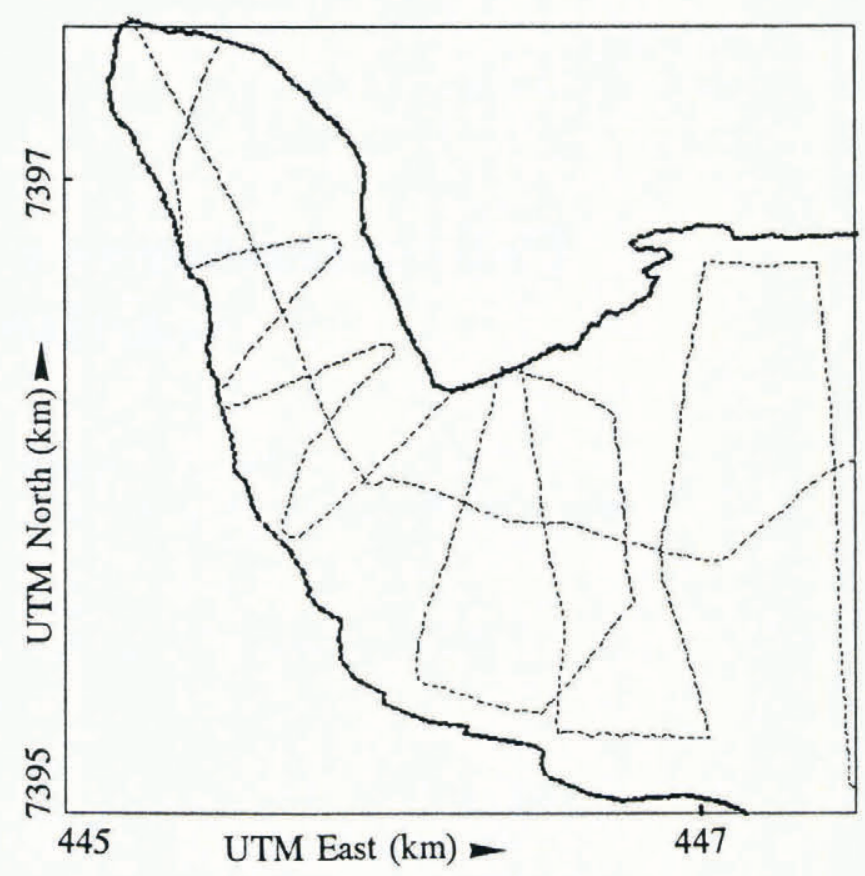

Fig. 3. Radar profiles flown over Engabreen.

that the helicopter causes minimal disturbance to the radar signals.

The radar transmitter is part of a ground-based Icelandic system (Sverrisson and others, 1980). The receiver consists of a digital storage oscilloscope connected to a portable computer. The antennae are resistively loaded dipoles as described by Sverrisson and others, but with lower resistance values to improve antenna efficiency. The centre frequency of the transmitted pulse is approximately $8 \mathrm{MHz}$.

The radar transmitter and battery are attached to the mast close to the transmitter antenna. A coaxial cable carries signals from the receiver antenna up to the oscilloscope in the helicopter. A pre-amplifier can be inserted between antenna and cable but was not necessary on Engabreen. The direct signal (airwave) from transmitter to receiver is powerful and reliable in this broadside parallel antenna configuration, and is used to trigger the oscilloscope. Received signals (shots) are digitized, averaged and transfered to the computer. Each average is time-stamped for correlation with position data. Radar data can be plotted off-line as single echoes or colour-modulated profiles (echograms). Measurements over open water are used to calibrate the time origin for the received signals, and give a useful check on the shape of the transmitted pulse.

\section{MEASUREMENTS ON ENGABREEN}

The measurements used to construct the bed topography map were conducted on a single day in June, 1991. One length profile and 15 cross profiles were flown (Fig. 3 ) in a total of two hours including a short stop to replace a damaged cable. The helicopter was flown c. $100 \mathrm{~m}$ above the ice surface such that the surface echo was distinct from the direct signal. The helicopter's radar altimeter did not appear to interfere with the radio-echo signals. GPS 


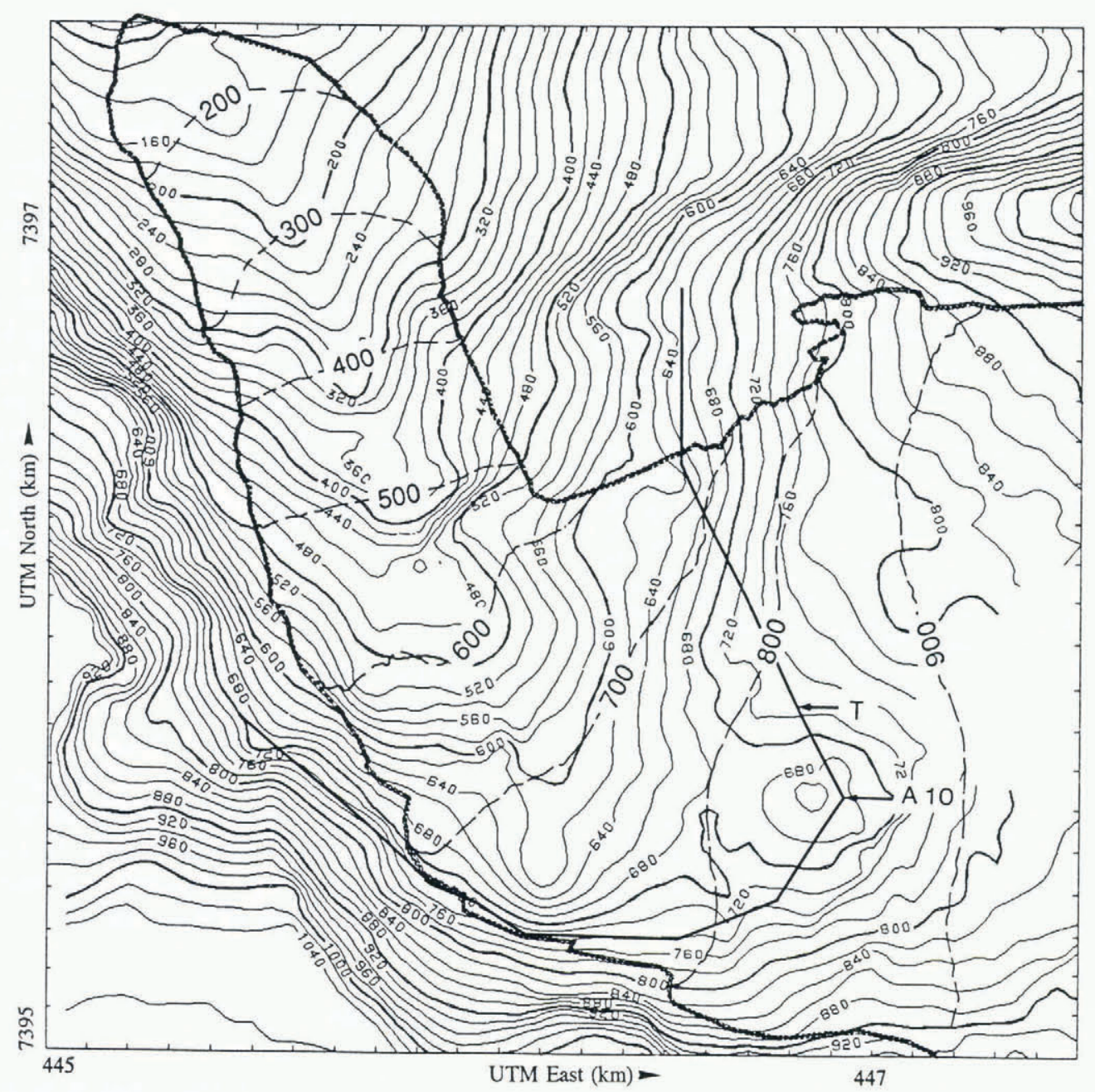

Fig. 4. Bed and ice surface (dotted) contours for Engabreen. Values are in $m$ a.s.l. A part of the water tunnel under Engabreen is also shown ( $T$ ).

satellite navigation was used to steer the helicopter along a pre-determined route at a speed of between 2 and $8 \mathrm{~m} \mathrm{~s}^{-1}$. Helicopter position was logged using GPS and a digital barometer. Three-dimensional GPS position fixes were obtained throughout the flying. The U.S. Department of Defense degradation of satellite data known as Selective Availability was not in operation during the radar measurements. We assume therefore that the error in GPS horizontal position is $\pm 20 \mathrm{~m}$.

The steep ice surface slope $\left(\right.$ c. $\left.20^{\circ}\right)$ must be taken into account in calculating the position of the bed reflection point. It is assumed here that the line between the antenna mast and bed reflection point is perpendicular to the ice surface locally. The radar data were processed to remove systematic noise. Bed echoes could not be obtained for ice thicknesses greater than approximately $200 \mathrm{~m}$ due to the relatively slow averaging of the oscilloscope used (Tektronix 222, averaging three shots/ s), giving a poor signal-to-noise ratio. There is however good agreement, to within $\pm 10 \mathrm{~m}$ ice thickness, at profile intersections. Bed coordinates were calculated along the profiles and used in a krige- interpolation in order to construct a map of the bed topography. The resulting contour map is shown in Figure 4.

Uncertainties in bed elevation arise due to interpretation of the echograms $( \pm 15 \mathrm{~m})$, antenna elevation $( \pm 5 \mathrm{~m})$ and the interpolation (uncertainty dependent on distance to nearest data points). The $\pm 20 \mathrm{~m}$ error in horizontal position contributes $\pm 7 \mathrm{~m}$ in bed elevation.

Some ice thickness data exists already in connection with the hydropower scheme. A total of 61 holes were hotwater drilled in 1975 and 1987 in two transverse profiles on Engabreen (Kennett, 1988), and the Svartisen plateau was mapped in 1986 (Sætrang, 1988). However radioecho data could not be obtained within $2.7 \mathrm{~km}$ of the water tunnel (Fig. 4) due to crevasses.

Figure 4 is largely consistent (within the uncertainties quoted above) with the bed elevations obtained from hotwater drilling. A comparison of interpolated radar and drilling data along the path of the water tunnel (Fig. 4) gives a standard deviation of $20 \mathrm{~m}$. However at point A10 (Fig. 4) in a trough in the bed topography, the discrepancy is considerably larger. Bed elevation from the radar data is $665 \pm 20 \mathrm{~m}$, compared to $635 \pm 15 \mathrm{~m}$ from hot-water drilling, and an elevation of $620 \pm 5 \mathrm{~m}$ obtained at $\mathrm{A} 10$ by drilling from the water tunnel to the base of the glacier. The inconsistency is probably due to a weak bed echo at this point and radar reflections from the sides of the trough. In general the form of the bed topography in Figure 4 is in agreement with that expected from the ice surface topography.

The radar receiver has been improved following the 


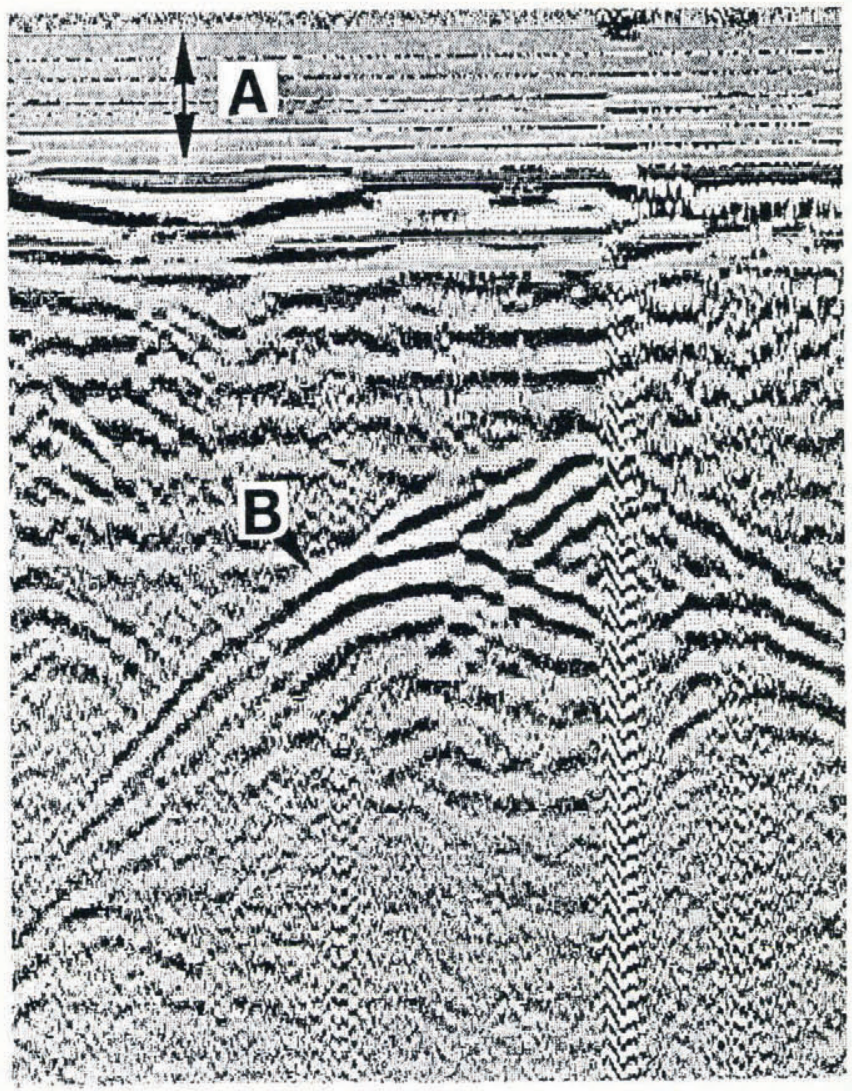

Fig. 5. An example echogram from Engabreen. The width of the echogram corresponds to 2.5 minutes flying time (approx. $800 \mathrm{~m}$ along profile), and the total height to $3.8 \mu$ s (equivalent to $320 \mathrm{~m}$ of ice thickness). The echo from the ice surface is largely obscured by the powerful airwave $(A)$, however the bed echo $(B)$ is clearly visible.

June 1991 measurements in order to increase the maximum measureable ice thickness. By digitizing and averaging shots at a rate of 200 shots/s (with a LeCroy $9310 \mathrm{M}$ oscilloscope), depth penetration has been increased to around $350 \mathrm{~m}$. Figure 5 shows an example echogram obtained on Engabreen in April 1992. Use of a lower centre frequency (longer antennae) and a more powerful transmitter, together with a reduction in helicopter speed and more sophisticated processing of the radar data, are expected to increase further the maximum depth penetration.

\section{CONCLUSION}

The combination of a digital radar and a hanging antenna support has enabled low frequency echo sounding of up to $350 \mathrm{~m}$ of temperate ice from a helicopter. The bed topography map derived for the lower part of Engabreen is consistent with other measurements except for one area where weak signals and side reflections made interpretation of the echograms difficult. The results show that scattering from crevasses, radar loss at the air-ice interface and helicopter interference are not insurmountable problems. The radar enables echo sounding in ice falls where thickness measurements have not previously been possible. It may also prove to be a more effective method of measuring ice thickness even where ground-based measurements are possible.

\section{ACKNOWLEDGEMENTS}

The authors thank Bjørn Wold for encouragement throughout the development of the radar, and $\mathrm{A} / \mathrm{S}$ Lufttransport (Helicopter Service) for help in the field and considerable patience during flying. The radar measurements on Engabreen were commissioned by the Construction Division of Statkraft.

\section{REFERENCES}

Kennett, M. I. 1988. Dybdemålinger og forsøk på lokalisering av subglasiale elvelop på Engabreen 1987. Oslo, Norwegian Water Resources and Energy Administration.

Sætrang, A.C. 1988. Kartlegging av istykkelse på Vestre Svartisen 1986. Oslo, Norwegian Water Resources and Energy Administration.

Sverrisson, M., Æ. Jóhannesson and H. Björnsson. 1980. Radio-echo equipment for depth sounding of temperate glaciers. F. Glaciol., 25(93), 477-486.

Watts, R.D. and A.W. England. 1976. Radio-echo sounding of temperate glaciers: ice properties and sounder design criteria. J. Glaciol., 17(75), 39-48.

Watts, R.D. and D. L. Wright. 1981. Systems for measuring thickness of temperate and polar ice from the ground or from the air. F. Glaciol., 27(97), 459-469.

The accuracy of references in the text and in this list is the responsibility of the authors, to whom queries should be addressed. 